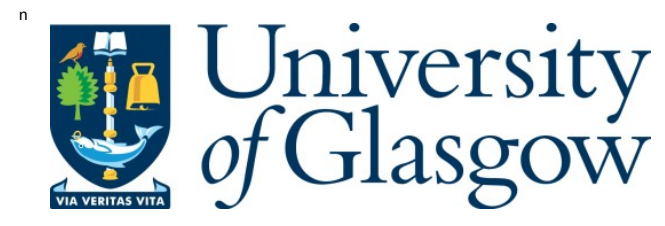

Miller, G. (2014) Is the agenda for global mental health a form of cultural imperialism? M edical Humanities, 40 (2). pp. 131-134. ISSN 1468-215X

Copyright @ 2014 B M J Publishing Group

A copy can be downloaded for personal non-commercial research or study, without prior permission or charge

Content must not be changed in any way or reproduced in any format or medium without the formal permission of the copyright holder(s)

http://eprints.gla.ac.uk/91491/

Deposited on: 18 N ovember 2014

Enlighten - Research publications by members of the U niversity of Glasgow http://eprints.gla.ac.uk 


\section{MEDICAL HUMANITIES}

\section{Is the agenda for global mental health a form of cultural imperialism?}

\begin{tabular}{|r|l|}
\hline Journal: & Medical Humanities \\
\hline Manuscript ID: & medhum-2013-010471.R1 \\
\hline Article Type: & Current controversies \\
\hline Date Submitted by the Author: & n/a \\
\hline Complete List of Authors: & Miller, Gavin; University of Glasgow, School of Critical Studies \\
\hline & $\begin{array}{l}\text { psychiatry }<\text { Mental health care, cross-cultural studies }<\text { Anthropology, } \\
\text { literary theory }<\text { Literature, philosophy of medicine/health care }< \\
\text { Philosophy }\end{array}$ \\
\hline
\end{tabular}

\section{SCHOLARONE ${ }^{\text {TM }}$ \\ Manuscripts}


Title: Is the agenda for global mental health a form of cultural imperialism? [Current controversy series]

Corresponding Author: Dr Gavin Miller, School of Critical Studies, University of Glasgow, 4 University Gardens. gavin.miller@glasgow.ac.uk Tel: 07986006567

Co-authors: None

Keywords: global mental health, cultural imperialism, transcultural psychiatry, globalization Word count: 3364 


\begin{abstract}
The contemporary agenda for global mental health has been criticized by some commentators as a form of cultural imperialism that extinguishes non-Western cultures of mental illness and healing. However, while cultures of mental illness and therapeutics may indeed be globally converging, models of cultural extinction (and their corresponding preservationist ethic) are highly problematic, particularly with regard to culturally dependent psychopathology. The more important issue is the possibility of a mutually enriching dialogue between various Western and non-Western cultures of mental illness and healing, rather than the desire to preserve difference simpliciter, whether in the name of cultural essentialism, or as part of a commitment to a global mosaic of cultural diversity.
\end{abstract}

The contemporary agenda for global mental health has met with sustained criticism from some commentators. This article evaluates one important strand of such appraisal: that in which the dissemination of Western mental health expertise is disparaged as a form of cultural imperialism. Derek Summerfield has vigorously criticised the contemporary global mental health agenda - a manifesto exemplified by the WHO's 2008 document $m h G A P$, an 'action programme developed for countries especially with low and lower middle incomes for scaling up services for mental, neurological, and substance use disorders'[1]. The programme proposes interventions designed to close various 'treatment gaps' between High Income Countries and Low or Middle Income Countries. mhGAP cites, for example, a survey showing that around $80 \%$ of people with serious mental, neurological, and substance abuse disorders in so-called 'less-developed countries' had received no treatment in the previous 12 months, set against a proportion of ' $35-50 \%$ ' for the same group in 'developed countries' (p. 7 in World Health Organization[1]). Summerfield stringently criticises this kind of manifesto, arguing that such 'psychiatric universalism risks being imperialistic'[2]. Scaling up psychiatric services to close the presumed gap in mental health provision extinguishes local 
ways of expressing and dealing with distress, replacing them with particularly Western ways: 'in globalising Western mental health, we are globalising a contemporary Western way of being a person' (p. 5 in Summerfield[2]).

In a similar vein, Ethan Watters objects to the spread of Western psychiatric models:

Americans have been industriously exporting their ideas about mental illness. ... they've failed to foresee the full impact of these efforts. It turns out that how a people in a culture think about mental illnesses - how they categorize and prioritize the symptoms, attempt to heal them, and set expectations for their course and outcome - influences the diseases themselves. In teaching the rest of the world to think, they have been, for better and worse, homogenizing the way the world goes mad.[3]

Watters argues that Western psychiatry is a culturally dependent therapeutics fitted to culturally dependent Western psychopathologies such as (he believes) depression and anorexia. He therefore declares that, because of the globalization of US psychiatry, 'Modes of healing and culturally specific beliefs about how to achieve mental health can be lost to humanity with the grim finality of an animal or plant lapsing into extinction' (p. 8 in Watters[3]).

Although this article addresses a particular conceptual problem in contemporary critique of the global mental health agenda, there are potentially empirical challenges to Watters's thesis and its various analogues. Like Watters, Suman Fernando laments 'the imposition of bio-medical psychiatry across the world and opening of markets for Big Pharma that would follow'[4]. This remark betrays a rather homogeneous vision of Western psychiatry. The biomedical model of psychiatry may indeed be dominant in the West, but it is certainly not universally accepted: from anti-psychiatry to recent calls for a move beyond the 
current, putatively 'technological' paradigm in biomedical psychiatry[5], Western mental health care continues to be characterised as much by debate as by consensus. The extent to which such oppositional models have also been exported to LMICs remains unclear. More generally, there is much empirical research to be done before it can concluded that Watters's case studies, and others like them, typify the reception of Western psychiatry in LMICs. One might wonder, for instance, whether partnerships such as the Toronto Addis Ababa Psychiatry Project (TAAPP) lead to a different, more mutually reflexive and negotiated relationship between Western psychiatry and indigenous expertise. One of TAAPP's explicit aims, after all, is 'to creatively and usefully challenge the relative cultural isolation of western models of psychiatry'[6].

Thorough empirical investigation of the global mental health agenda and its consequences, extending to cultural impact, systemic outcomes, and patient outcomes, is surely essential. However, to the extent that cultures of mental illness and therapeutics are indeed globally converging on a Western and predominantly biomedical model, I shall argue that this should not be viewed as loss or extinction of non-Western ethnopsychiatries. (I use the term 'extinction', of course, without implying any broader analogy with biological evolution.) Concepts such as 'cultural extinction' (and even 'culture' itself) are, I believe, highly problematic, and should be removed from the terms of the debate. This would allow a more coherent critique to emerge in which the focus is not upon preserving diversity, but upon promoting the best forms of dialogue and interchange.

It is helpful to distinguish allies to the cultural extinction argument. A distinct, but aligned, argument highlights the wisdom of non-Western traditions. Alongside his concern at the opening of new markets for Big Pharma, Fernando calls for 
a framework of mental health care that is respectful of cultural diversity, acknowledging that there is much wisdom in non-western countries, that we can learn much from how other cultures handle human problems.[4]

There are at least two thoughts here. One is that we should protect cultural difference in itself - the request to be 'respectful of cultural diversity'. The other is that by so doing we preserve a reservoir of indigenous knowledge which one day might inform our own expertise. The demand to liberalise the global marketplace in psychiatric ideas (and practices), and to have genuinely reciprocal dialogue between forms of expertise, is particularly imperative given additional concerns about the risks of Western intervention. Watters, for instance, gives a social constructionist analysis of the way in which post-disaster counselling in LMICs may inadvertently make things worse by promoting psychological vulnerability (p. 131 in Watters[3]).

Opposition to Big Pharma, reciprocal recognition of non-Western expertise, and commendable clinical caution, are, however, quite distinct from the thesis that cultural diversity in mental illness and therapeutics is, in itself, desirable. Such a position is part of wider concern about so-called cultural imperialism. John Tomlinson notes that while 'cultures have always influenced one another and that this influence has often enriched the interacting communities', contemporary 'cultural synchronisation' is an 'unprecedented feature of global modernity'[7]. Cees Hamelink refers accordingly to an ongoing process of 'cultural synchronization' in which 'decisions regarding the cultural development in a given country are made in accordance with the interests and needs of a powerful central nation'[8].

Debates about cultural synchronization commonly centre on language, religion, art forms, and so forth. Hamelink complains, for instance, that 'the incredibly rich local musical tradition of many Third World countries is rapidly disappearing under the onslaught of dawn- 
to-dusk North American pop music' (p. 2 in Hamelink[8]). Such debates transpose to cultural difference in psychopathology and therapeutics. The most obvious relevant phenomena are culturally bound syndromes, where cultural difference itself is the fundamental pathogenic factor. These need little or no introduction: culturally specific conditions such as koro (penisretraction/shrinking) are recognised by official nosology. There are also more subtle cultural differences, such as variation in 'idioms of distress' - 'socially and culturally resonant means of experiencing and expressing distress in local worlds' [9]. Idioms may range from various psychological and somatic complaints, to seeking out healthcare and diagnosis, or even to just smoking more (pp. 405-6 in Nichter[9]). (There are also broadly similar concepts such as variation in the 'symptom pool', those 'templates, or different ways of presenting illness' held in a 'culture's collective memory of how to behave when ill'[10]). So it may be argued that the global mental health agenda promotes a psychiatrically-led homogenization in culturally dependent psychopathology, ranging from gross features such as culturally bound syndromes, to the particularities of idioms of distress.

But a fundamental question remains: why is such cultural convergence in itself a loss or destruction, analogous (following Watters), to 'an animal or plant lapsing into extinction'? This is a problem faced generally by what Anthony Appiah calls the 'preservationist ethic'[11], by which 'assimilation is figured as annihilation' (p. 130 in Appiah[11]). However, to defend the view of cultural synchronisation as extinction is harder than it might at first appear.

One could regard convergence as the loss to persons of what is culturally proper to them. Expressed in the first person, what is at stake is a loss of 'my' way of life, what is good 'for me', even - we suppose - right down to ways of being ill that are good 'for me'. The problem facing this account, however, is that 'one's culture could only be whatever it was that one actually practiced, and couldn't be lost or retrieved or preserved or betrayed' (p. 137 
in Appiah[11]). Walter Benn Michaels (whom Appiah follows) explains this argument in greater length:

that something belongs to our culture cannot count as a motive for our doing it since, if it does belong to our culture, we already do it and if we don't do it (if we've stopped or haven't yet started doing it), it doesn't belong to our culture. ... It is only if we think that our culture is not whatever beliefs and practices we actually happen to have but is instead the beliefs and practices that should properly go with the sort of people we happen to be that the fact of something belonging to our culture can count as a reason for doing it.[12]

Michaels and Appiah tend to exemplify with cultural features such as teaching Shakespeare in school. But their argument can be illustrated with ethnopsychiatric materials. If Consuelo from South America reads English-language pop psychology, and stops having ataques de nervios and starts having depression, then her depression is as much her idiom of distress as nervios used to be. If this change is to count as a loss of Consuelo's culture, then we need some sense of what Consuelo's idioms of distress should be - her 'real' or 'authentic' culture, as opposed to the one she actually has. As both Michaels and Appiah remark, this used to be done by categorizing people through explicitly racial or ethnic concepts (one might in Consuelo's case have invoked some kind of racial psychology). But now such categorization seems to be done merely by implicitly racial or ethnic thinking - there needs to be some conception of Consuelo's proper group (and its typical culture), for her changed idiom to count as loss rather than change. But what this might be is unclear. For commentators who view homogenization of culturally dependent psychopathology as extinction, the onus is on them to find an answer that avoids cultural essentialism - that does not posit a racial, ethnic, or national 'essence' lurking within Consuelo's soul, and which must find proper expression 
in her culture. (For the sake of brevity, I have expressed this counterargument in individualistic ethical terms. One might of course reframe the debate in terms of benefit or harm not to individuals but to groups. The problem still applies of trying to identify the 'real' culture of a group as opposed to the one it actually has. Indeed, group heterogeneity further erodes the preservationist view. Even if ataque de nervios happens to be culturally hegemonic, why is the subgroup consisting of Consuelo and others - her pop-psychology book club perhaps - in some sense untrue to their culture?)

But perhaps there is another way of seeing such change as loss. Might one think of Consuelo's changed idiom not as a loss 'for her' (or 'for them'), but rather as a loss to global cultural diversity - to the 'external diversity' apparent when the world is viewed as 'a grid of communities hewing each to its own customs and creed' (p. 149 in Appiah[11])? Such preservationism is not motivated by a sense of cultural propriety, but by the desire to protect a mosaic of differences, including even the difference between distress as ataque de nervios and distress as depression. This model, which resonates with ideas of biodiversity, is, however, vulnerable to the charge of ethnocentrism, and may be viewed as an extension of Western global dominance. The Western expert speaks on behalf of the putatively threatened 'other', demanding 'preservation' much as the earlier imperialists demanded 'education' and 'enlightenment'. As Tomlinson remarks, 'the problem of homogenisation is likely to present itself to the Western intellectual who has a sense of the diversity and "richness" of global culture as a particular threat'; but 'we cannot, without irony, argue that the Western intellectual's (informed?) concern is more valid' (p. 109 in Tomlinson[7]). Why should we discourage Consuelo from being depressed, as opposed to having an ataque de nervios? Appiah allows that there may be an aesthetic (or even curiosity) value to the Western spectator in preserving external diversity, but 'it would be a moral error to take measures ... to discourage members of these picturesque communities from leaving and joining ours' (p. 
150 in Appiah[11]). Consuelo deserves better than being urged to stay in her niche in some great cabinet of ethnopsychiatric curiosities.

A further problem should be noted. While idioms of distress will presumably always be needed, things are different with culturally bound syndromes, where culture itself is the fundamental cause (analogous to a biological pathogen). If koro dies out, then this cultural extinction, as with the extinction of the smallpox virus, simply means one less ill (or illness) in the world. We can speculate about the consequences of such an extinction, and whether they might be better or worse (perhaps koro prevents something even worse from happening). But all other things being equal, it is hard to see why the world is better for the existence of koro, or would not be improved without it. In other words, where cultural convergence in psychopathology does have axiological significance, it may be precisely as a benefit.

Given such objections, why do critics of the global mental health agenda allude to cultural extinction? One answer lies in what Tomlinson regards as the "constant temptation for the Western cultural critic to displace their own cultural dilemmas on to concern for other cultures' (p. 120 in Tomlinson[7]). When Summerfield warns that 'in globalising Western mental health, we are globalising a contemporary Western way of being a person' what worries him is perhaps not the loss of other ways of being a person simpliciter, so much as the replacement of a more socially embedded and resilient selfhood by a Western model in which 'citizens are invited to see a widening range of experiences in life as inherently risky and liable to make them ill' (p. 520 in Summerfield[2]). In other words, what is at stake is not the loss of any old difference, but rather the loss of a more resilient way of life, and a corresponding local wisdom.

That the real concern of Summerfield and others is - or should be - not diversity in itself, but the failings of biomedical psychiatry, and the merits of non-Western ethnopsychiatry, becomes apparent when one extrapolates from the preservationist ethic. If 
we are indeed to view convergence in culturally dependent psychopathology as extinction, then this must also - in principle - apply to Western ethnopsychiatry. Summerfield provides the example of a local healer at work in a South African township; this gentleman 'would doubtless have no problem in accepting the statement that his was merely one of many ethnopsychiatries in the world' (p. 527 in Summerfield[2]). The difficulty, Summerfield continues, is that 'Western psychiatry simply refuses to do the same' (p. 527 in Summerfield[2]). Accept, for the sake of argument, that Western psychiatry is indeed one ethnopsychiatry amongst others. We could imagine some hypothetical science-fiction scenario in which Western ethnopsychiatry becomes the property of an embattled society perhaps global warming has brought about a decline in Western dominance. An ethnographer in this new world might record the British natives' peculiar rituals and idioms of distress: consulting the jeepee or the sike-a-trist to request conversational therapy or pills, and locating suffering in an internal, personal spirit-ghost, rather than in their body. Such an account might end with an echo of Watters's warning that 'modes of healing and culturally specific beliefs about how to achieve mental health can be lost to humanity with the grim finality of an animal or plant lapsing into extinction'. Yet such a call for preservation is of course very much in tension with critique of Western psychiatry, even if it is a coherent extrapolation from the preservationist position towards non-Western psychiatries.

There is then a clear strand of criticism of the global mental health agenda that is willing to evaluate different ethnopsychiatries, and their relative merits, and such appraisal is quite distinct from the preservationist ethic, even if the two positions are frequently muddled. This equivocation arises, I suspect, because critique has been informed by transcultural psychiatry, a field which saw a treaty, as it were, between psychiatry and anthropology to share 'epistemic authority' - 'the legitimate power to define, describe, and explain bounded domains of reality'[13] - over a particular domain of mutual interest. This epistemological 
dual sovereignty imported into psychiatric discourse the anthropological notion of culture, succinctly defined by Laurence Kirmayer as 'a way of life: the values, customs, beliefs and practices that form a complex system'[14]. However, as Adam Kuper explains,

appeals to culture can offer only a partial explanation of why people think and behave as they do, and of what causes them to alter their ways. Political and economic forces, social institutions, and biological processes cannot be wished away, or assimilated to systems of knowledge and belief.[15]

To the question 'Why do these people do things differently?', the concept of culture furnishes the answer, 'Because they have a different way of doing things'.

As noted above, few informed commentators would apply such a limited analysis to Western psychiatry. Summerfield, Fernando, and Watters, are all aware that an adequate understanding of biomedical psychiatry requires more than just description of a particular culture, without reference to wider social, historical, and political context. But while one may well plausibly argue that Western psychiatry is bound up with a neoliberal capitalist system, this should not prevent inquiry into the ideologies of non-Western ethnopsychiatries. Can we not turn to the South African township healer - or other equivalent - and ask not about cultural difference, but about the inequalities, ideologies and untruths of such practices? There is comparatively little discussion of such concerns in critique of the global mental health agenda, where the hermeneutics of suspicion are generally turned back upon the West. Indeed, there is a risk of recapitulating the old civilization-culture binary. We have critique of a psychiatric ideology that accommodates and legitimizes our complex neoliberal economic, social, and political system. They have an ethnopsychiatry that exists in a complex, fragile, but ultimately harmonious cultural ecosystem. To express the contrast more concretely: 
Oppositional Defiant Disorder is a daft, downright harmful myth promulgated by the American Psychiatric Association; but koro is an imperilled resource for expressing distress within local systems of meaning.

There is much that is convincing in contemporary critique of the global mental health agenda. But sceptics should reflect carefully on the strand of critique that employs ideas of cultural imperialism. This strand should be scrutinised with a view to properly assessing the commitment to cultural diversity as a value in itself. I believe critique will be improved by abandoning the preservationist ethic, which obscures far stronger arguments, particularly those which see not difference per se, but rather unrecognized expertise, in non-Western traditions. The more important issue is the possibility of a mutually enriching dialogue between different forms of healing expertise, rather than the desire to preserve difference simpliciter, whether in the name of cultural essentialism, or as part of a commitment to a global mosaic of cultural diversity. John Briggs and Joanne Sharp argue that 'it is important not to see indigenous knowledge as an artefact, simply something to be preserved (perhaps akin to the collection of genetic diversity)', but rather to recognize that 'indigenous knowledges all over the world are malleable, altering in response to Western ideas and practices'[16]. Rather than focussing on the putative extinction of culturally dependent psychopathologies and therapeutics, critics of the global mental health agenda should articulate their preferred model for ethnopsychiatric interchange, commerce, and transformation. What can we learn from them, and they from $u s$, and under what conditions is such dialogue best undertaken? An answer to this question is beyond the scope of this article, but I hope that my contribution may encourage debate to shift away from the preservationist ethic, and to focus more intensively upon what would count as a genuine and mutually enriching conversation. 


\section{Works Cited}

1. World Health Organization. mhGAP: Mental Health Gap Action Programme: scaling up care for mental, neurological and substance use disorders. Geneva: WHO Press, 20083.

2. Summerfield D. Afterword: against 'global mental health'. Transcult. Psychiatry 2012;49:519-30 525.

3. Watters E. Crazy Like Us: The Globalization of the Western Mind. London: Constable \& Robinson, 20112.

4. Fernando S. A 'global' mental health program or markets for big pharma? Open Mind 2011(168):22.

5. Bracken $\mathrm{P}$, Thomas $\mathrm{P}$, Timimi $\mathrm{S}$, et al. Psychiatry beyond the current paradigm. Br. $J$. Psychiatry 2012;201:430-34.

6. Anon. Toronto Addis Ababa Psychiatry Project: Faculty and Resident Information, 2009. http://www.utoronto.ca/ethiopia/fac_res_info.htm (accessed 14 February 2014).

7. Tomlinson J. Cultural Imperialism: A Critical Introduction. London: Pinter, 1991110.

8. Hamelink CJ. Cultural Autonomy in Global Communications: Planning National Information Policy. New York \& London: Longman, 198322.

9. Nichter M. Idioms of distress revisited. Cult., Med. and Psychiatr. 2010;34:401-16 405.

10. Shorter E. From Paralysis to Fatigue: A History of Psychosomatic Illness in the Modern Era. New York: Simon \& Schuster, 19922.

11. Appiah KA. The Ethics of Identity. Princeton, NJ: Princeton University Press, 2005131.

12. Michaels WB. Our America: Nativism, Modernism, and Pluralism. Durham, NC: Duke University Press, 1995128.

13. Gieryn TF. Cultural Boundaries of Science: Credibility on the Line. Chicago: University of Chicago Press, 19991. 
14. Kirmayer LJ. Cultural psychiatry in historical perspective. In: Bhugra D, Bhui K, eds. Textbook of Cultural Psychiatry. Cambridge: Cambridge University Press, 2007:3-19 5.

15. Kuper A. Culture: the Anthropologists'Account. Cambridge, MA: Harvard University Press, 1999 xi.

16. Briggs J, Sharp J. Indigenous knowledges and development: a postcolonial caution. Third World Quarterly 2006;25(4):661-76 673.

The Corresponding Author has the right to grant on behalf of all authors and does grant on behalf of all authors, an exclusive licence (or non-exclusive for government employees) on a worldwide basis to the BMJ Group and co-owners or contracting owning societies (where published by the BMJ Group on their behalf), and its Licensees to permit this article (if accepted) to be published in Medical Humanities and any other BMJ Group products and to exploit all subsidiary rights, as set out in our licence. 